\title{
Investigation of thin film energy-saving coatings
}

\author{
Vyacheslav Bukhmirov ${ }^{1, *}$, Alexander Gaskov ${ }^{1}$ \\ ${ }^{1}$ Ivanovo State Power Engineering University, 153003 Ivanovo, Russia
}

\begin{abstract}
The report presents the results of an experimental study of the thermophysical properties and energy efficiency of thin-film energy-saving coatings consisting of hollow microspheres and a binder material from styrene-acrylic dispersion. The value of the thermal conductivity coefficient of the energy-saving paint is estimated depending on its composition and temperature, and the thermal diffusivity coefficient is determined. Experimental results of energy efficiency of using thin-film coatings for insulation of facades of buildings and as thermal insulation for pipelines with a hot coolant are presented.
\end{abstract}

\section{Introduction}

Reduction of heat losses is an urgent task of increasing the energy efficiency of heat networks and objects of housing and communal services. To reduce the loss of thermal energy use a variety of thermal insulation materials, which must have a number of special qualities, the main of which is a low value of the coefficient of thermal conductivity. The main share of the market ( $97 \%$ ) of thermal insulation materials is occupied by inorganic materials - mineral wool insulation and polyfoams [1]. At present, thin-film coatings (energy-saving paints), consisting of hollow microspheres and bonding materials that have the properties of paints, but with a lowered value of the coefficient of thermal conductivity, have become widely used to save energy.

\section{Statement of the Problem}

The analysis of the scientific literature has shown that the known data on the consumer and thermophysical properties of energy-saving paints differ significantly from each other, that is why the study of the properties of thin-film coatings on the basis of hollow microspheres is an actual scientific task.

\section{Experiment and processing}

\subsection{Investigation of thermophysical properties}

\footnotetext{
* Corresponding author: buhmirov@tot.ispu.ru
} 
This section presents the results of the experimental determination of the thermal conductivity coefficient of energy-saving paint as a function of temperature and mass content of MC-V2L hollow glass microspheres in a binder of styrene-acrylic dispersion "Acrylan 101" and experimental values of the thermal diffusivity of energy-saving paint, Produced at a chemical enterprise in the city of Ivanovo.

An estimate of the thermal conductivity was made experimentally for energy-saving paint samples with a mass content of microspheres of $8 \%, 25 \%$ and $32.6 \%$ in acrylic binder and for a sample of acrylic coating without addition of microspheres. The thickness of the test samples was: $1.5 \mathrm{~mm}$ for a binder with the addition of microspheres and $1 \mathrm{~mm}$ for pure acrylic. The coefficient of thermal conductivity of the samples was obtained on a laboratory bench by the method of a cylindrical layer in the steady-state regime of thermal conductivity. A series of experiments was performed at different values of the heat flux passing through the samples under study.

The coefficient of thermal diffusivity of energy-saving paint was found by the regular regime method using a modified air " $\alpha$-calorimeter", in which the test sample was asymmetrically heated longitudinally by the flow of hot air around it. The air flow velocity was chosen so that the condition of the thermally thick body $\mathrm{Bi}>100$ was satisfied for the heated sample. The test sample are made in the form of parallelepiped with dimensions of $45 \times 60 \times 75 \mathrm{~mm}$, made of energy-saving paint with a mass content of microspheres of $32.6 \%$ in a binder of acrylic. The sample, insulated with mineral wool on all sides except the working surface, was blown by a stream of hot air from the supercharger with a built-in heater. Using a supercharger control unit, it was possible to change the speed and temperature of the air flow in the interval of $0 \div 20 \mathrm{~m} / \mathrm{s}$ and $20 \div 120^{\circ} \mathrm{C}$, respectively. During the experiments, the speed and temperature of the air flow were measured using a MES$200 \mathrm{~A}$ meteometer with a velocity measurement error of $\pm 1.5 \mathrm{~m} / \mathrm{s}$ and a temperature of $\pm 0.5^{\circ} \mathrm{C}$. The temperature of the sample at three points (in the center, on the upper and lower faces) is determined using thermocouples of type " $T$ " and a secondary device ADAM-4000 with an error of measurement of $\pm 1^{\circ} \mathrm{C}$. A series of experiments was performed at different air temperature values.

\subsection{The study of energy efficiency}

This section presents the results of a energy efficiency study of energy-saving paints used for the building facades insulation and as thermal insulation for pipelines with a hot coolant.

The study of the energy efficiency of energy-saving paints for the warming of the facades of buildings was carried out at a full-scale research site installed on the wall of a residential building. The landfill is pre-plastered with cement mortar $10 \mathrm{~mm}$ thick, a section of the house wall divided into zones of $3.9 \mathrm{~m}$ high and $2 \mathrm{~m}$ wide with various types of thermal insulation. To study the energy efficiency, the following types of coatings were used:

A) At the plot No. 1 of the polygon, the thermal insulation is made using the technology of a "wet" facade made of mineral wool $(\delta=100 \mathrm{~mm}, \lambda=0.038 \div 0,042 \mathrm{~W} /(\mathrm{m} \cdot \mathrm{K}), \rho=131 \div 135$ $\left.\mathrm{kg} / \mathrm{m}^{3}\right)$;

B) In plots 2 and 3, the thermal insulation is made by applying an energy-saving paint layer of $1 \mathrm{~mm}$ and $3 \mathrm{~mm}$, respectively. To ensure the same thickness of the layers, the energy-saving paint was applied to the wall by the machine using a spray gun.

C) Plot No. 4 of the landfill was covered only with $10 \mathrm{~mm}$ thick cement plaster without applying energy-saving coatings.

During the experiments, the heat fluxes and temperatures on the surfaces of the experimental sections were measured by the ITP-MG4.03 / X (I) "Potok" instrument with a 
measurement error of the heat flux of $\pm 6 \%$ and a temperature of $\pm 0.2^{\circ} \mathrm{C}$; Temperature between the layers of coatings and the temperature of the external surfaces of each experimental area measured by thermocouples type " $T$ " with the secondary device ADAM4000 which had an error of measurement of $\pm 1^{\circ} \mathrm{C}$; The outside temperature with the help of the weather station Davis AdvantagePro2 with a measurement error of $0.5^{\circ} \mathrm{C}$.

To investigate the effectiveness of energy-saving paints with the reducing heat losses from hot water pipelines, a series of experiments was carried out at a thermal station in which there were two water supply lines with a diameter of $219 \mathrm{~mm}$ and a length of 2300 $\mathrm{mm}$ are located. Due to the high water cut of the heat point, the service personnel use the pipelines as gangways to pass to the stop valves, which leads to mechanical damage to the thermal insulation and its waterproofing layer. Therefore, the thermal insulation gets wet, and high humidity leads to corrosion of the metal pipelines. To reduce corrosion of the metal and reduce the heat loss of the coolant, it was proposed to cover the pipelines with energy-saving paint with a thickness of $\delta=2.5 \pm 0.2 \mathrm{~mm}$. The efficiency of using energysaving paint was determined by comparing the outer wall of pipelines temperature and heat flows from their surface "before" and "after" the application of a thin-coating coating. Between the measurements, the heat point and the painted pipelines were flooded with hot water due to an accident on the heating main.

\section{Results and Discussion}

As a result of the research:

1) The average value of the coefficient of thermal conductivity in the temperature range $20 \div 100^{\circ} \mathrm{C}$ was: for the binder (acrylic) $-\sim 0.028 \mathrm{~W} /(\mathrm{m} \cdot \mathrm{K})$; At $8 \%$ content of microspheres in energy-saving paint by weight $-\sim 0.025 \mathrm{~W} /(\mathrm{m} \cdot \mathrm{K})$; At $25 \%$ microsphere content $-\sim 0.022$ $\mathrm{W} /(\mathrm{m} \cdot \mathrm{K})$; At a $32.6 \%$ content of microspheres - $\sim 0.019 \mathrm{~W} /(\mathrm{m} \cdot \mathrm{K})$. The coefficient of thermal conductivity of the energy-saving paint in the temperature range $20 \div 100^{\circ} \mathrm{C}$ with an error of no more than $12 \%$ can be approximated by the formula, $\mathrm{W} /(\mathrm{m} \cdot \mathrm{K})$ :

$$
\lambda=\frac{2.24}{10^{4}} T-\left(\frac{2.44}{10^{6}} T+\frac{1.27}{10^{4}}\right) C+\frac{1.61}{10^{2}}
$$

where $\mathrm{C}$ is the mass concentration of microspheres, $\%$; $\mathrm{T}$ is the temperature, ${ }^{\circ} \mathrm{C}$.

2) The average thermal diffusivity of the energy-saving paint is in the range $2.7 \cdot 10^{-8} \div 3.1 \cdot 10^{-8} \mathrm{~m}^{2} / \mathrm{s}$.

3 ) It is established that the thermal losses of the building during the application of heat insulation by the technology of a "wet" facade made of mineral wool slabs with a thickness of $100 \mathrm{~mm}$ are reduced by $62 \%$, when the energy-saving paint is applied in layers of $1 \mathrm{~mm}$ and $3 \mathrm{~mm}$, the heat losses are reduced by $8.3 \%$ and $11.8 \%$ Respectively. At the same time, the thermal losses from the surface were taken as the base value of heat losses without applying energy-saving coatings (plot No. 4).

4) Data are obtained on the value of the average integral degree of blackness of the insulating materials being studied. In the temperature range $-20 \div 0^{\circ} \mathrm{C}$, the average integral degree of blackness in all thermal protection coatings studied is $0.96 \div 0.98$.

5) The effect of hot water with a temperature of $\sim 60^{\circ} \mathrm{C}$ for 5 days did not lead to the destruction of the layer of energy-saving paint, which indicates the resistance of this type of thin-film coating to the action of hot water with a temperature of $\sim 60^{\circ} \mathrm{C}$. It was experimentally established that after deposition of a thin-film coating, first, the heat losses decreased from the direct pipeline by $42.5 \%$, and from the return pipeline by $63.4 \%$ and, secondly, the surface temperature of the direct pipeline decreased by $17^{\circ} \mathrm{C}$, and the surface temperature of the return pipeline is $23.1{ }^{\circ} \mathrm{C}$. 


\section{Conclusions}

1. The main thermophysical properties of thin-film energy-saving coatings based on hollow microspheres are determined. The obtained data can be used in engineering calculations and mathematical modeling of heat transfer processes.

2. At values of thermal conductivity coefficient for energy-saving paints and mineral wool insulation of the same order to achieve the same energy-saving effect, the thickness of energy-saving paint and mineral wool insulation should be comparable, which is economically unprofitable. However, in conditions of high humidity, the thermal insulation properties of mineral-wool heat-insulating materials deteriorate sharply and the use of thinfilm coatings from energy-saving paint becomes an economically viable energy-saving measure.

\section{References}

1. O.A. Ignatova, Technology of insulating building materials and products. Part 2. Heatand hydro-insulating materials and products: training. (Publishing Center Academy, Moscow, 2012) [In Russian] 